\title{
Dietary Bisphenol A Suppresses the Growth of Newborn Pups by Insufficient Supply of Maternal Milk in Mice
}

\author{
Chiho Matsumoto, Chisato Miyaura, ${ }^{*, 1}$ and Akira Ito \\ Department of Biochemistry, School of Pharmacy, Tokyo University of Pharmacy and Life Science, 1432-1, Horinouchi, Hachioji Tokyo \\ 192-0392, Japan
}

(Received February 18, 2004; Accepted March 2, 2004)

Bisphenol A (BPA), a monomer used for the production of polycarbonate, is known to have estrogen activity. In this study, pregnant mice were fed chow diet containing $1 \% \mathrm{BPA}$, and we examined the influence of dietary BPA on delivery and growth of newborn pups in mice. When pregnant mice were fed BPA diet, the mice normally delivered pups on day 21 of gestation. The number of offspring pups in maternal mice fed BPA diet was same to those fed normal diet. Therefore, the growth of fetuses and the process of delivery were not influenced by dietary BPA. However, the growth of newborn pups was markedly suppressed when maternal mice were fed BPA diet. The growth of neonatal mice depends on breast milk, and stomach was filled with milk in pups. In newborn pups from maternal mice supplemented with BPA diet, the weight of stomach was lower than that from maternal mice with normal diet. Since the serum level of prolactin was limited in maternal mice supplemented with BPA diet, the suppressed growth of newborn pups by dietary BPA may be due to the insufficient supply of breast milk. These results suggest that the influence of BPA on the growth of newborn pups is related to hormonal condition in maternal mice.

Key words — bisphenol A, breast milk, growth of pups, prolactin

\section{INTRODUCTION}

Bisphenol A (BPA) is a class of monomer widely used in the production of polycarbonate plastic prod-

\footnotetext{
${ }^{1}$ Present address: Department of Biotechnology and Life Science, Tokyo University of Agriculture and Technology, 2-2416, Nakamachi, Koganei, Tokyo 184-8588, Japan

*To whom correspondence should be addressed: Department of Biotechnology and Life Science, Tokyo University of Agriculture and Technology, 2-24-16, Nakamachi, Koganei, Tokyo 184-8588, Japan. Tel. \& Fax: +81-42-388-7390; E-mail: miyaura@cc.tuat.ac.jp
}

ucts. The level of human exposure to BPA is not insignificant, as microgram amounts of BPA were reported to be detectable in liquid from canned vegetables. ${ }^{1)}$ Since children are thought to be more sensitive to endocrine disrupters including BPA than adults, the influence of the exposure of BPA may depend on age and hormonal condition. BPA binds to estrogen receptor with approximately 10000 times less affinity than $17 \beta$-estradiol and it exhibits estrogenic activity both in vitro and in vivo assay systems. ${ }^{2)}$ In vivo assay, BPA enhances the uterine weight in immature animals, and accelerate the onset of puberty. ${ }^{3)}$ It is known that BPA exhibits estrogenic properties in sexual organs, but the effects of BPA in vivo are still not clear.

Estrogens are synthesized from androgens by aromatase (CYP19). ${ }^{4)}$ We have reported that aromatase-deficient (ArKO) mice show underdeveloped uteri and mammary gland, bone loss by increased bone resorption and abnormal lipid metabolism. ${ }^{5-7)}$ All of these phenotypes in ArKO mice are due to estrogen deficiency caused by loss of aromatase, and the replacement of estrogen restore these phenotypes to normal. When ArKO were fed chow diet supplemented with $0.1 \%$ or $1 \%$ BPA, they were protected from ovarian degeneration, uterine diminution and bone loss in a dose-dependent manner. ${ }^{8)}$ Therefore, estrogenic effects of BPA on the reproductive tract as well as skeletal tissue were evident in adult female ArKO mice. Since ArKO mice completely lose estrogen synthesis, ArKO is a useful animal model for characterization of estrogenic compounds. However, the influence of estrogenic compounds in normal animal may be related to the hormonal condition in vivo especially in females.

In this study, we focused on the influence of BPA on pregnant mice to clarify the effects of BPA on delivery and lactation of maternal mice. Here we show that the growth of newborn pups was mark- 
edly suppressed by the insufficient supply of breast milk, when maternal mice were fed chow diet supplemented with BPA.

\section{MATERIALS AND METHODS}

\author{
Materials — A standard rodent chow (CE-2)
} was obtained from Japan Clea (Tokyo, Japan). BPA $(\geq 97 \%)$ was purchased from Sigma (St. Louis, MO, U.S.A.). The chow diets supplemented with BPA were prepared by impregnation with BPA, which was dissolved in acetone, as reported previously. ${ }^{8)}$ For example, $1 \mathrm{~g} \mathrm{BPA}$ was dissolved in $10 \mathrm{ml}$ acetone and impregnated into $100 \mathrm{~g}$ rodent chow to yield the chow diet supplemented with $1 \%(\mathrm{w} / \mathrm{w})$ BPA. The chow diets supplemented with BPA were newly prepared every other day.

Animals — Pregnant mice of $d d Y$ strain, on day 14 of gestation, were obtained from Japan SLC (Shizuoka, Japan). All animals were given water and rodent chow diet with or without BPA ad libitum. The absolute value of BPA given to pregnant mouse was $526 \mathrm{mg} / 14$ day/mouse. After delivery of maternal mice, body weight of offspring pups was monitored everyday. Pups were sacrificed on day 7 , and weight of stomach was measured. Animal care was in accordance with institutional guidelines.

\section{Serum Level of Prolactin in Maternal Mice}

Levels of serum prolactin were measured using individual serum samples collected from maternal mice on day 4 after delivery. Serum levels of prolactin were determined using mouse prolactin radioimmunoassay system (NIDDK's National Hormone and Peptide Program, CA, U.S.A.) according to the manufacture's instructions. Anti-mouse prolactin antiserum and iodinated mouse prolactin were added to the serum samples, and the reaction was allowed to proceed for $24 \mathrm{hr}$ at room temperature. After the addition of 2nd antibody, anti-rabbit $\gamma$-globulin goat serum, they were incubated at $32^{\circ} \mathrm{C}$ for $4 \mathrm{hr}$, centrifuged at $3000 \mathrm{rpm}$ for $20 \mathrm{~min}$ at $4^{\circ} \mathrm{C}$, and resulting pellets were used for the detection of ${ }^{125} \mathrm{I}$.

Statistical Analysis — The data are expressed as means \pm SEM. The significance of differences was analyzed using Student's $t$-test (two-tailed).

\section{RESULTS AND DISCUSSION}

\section{Influence of Dietary Bisphenol A on the Growth of Newborn Pups}

When pregnant mice on day 14 of gestation were started to feed chow diet containing $1 \% \mathrm{BPA}$, the mice normally delivered pups on day 21 of gestation, and the number of newborn pups in the maternal mice fed BPA diet was same to that in the maternal mice fed normal diet. Figure 1 shows the influence of BPA diet on the growth of newborn pups until day 7. On day 0 , body weight of pups from maternal mice fed BPA diet was similar to that of pups from maternal mice fed normal diet (Fig. 1A). However, body weight of pups in BPA diet group was lower than that of pups in normal diet group (Fig. 1AB), and $30 \%$ of pups in BPA diet group died until day 7 (Fig. 1C). Previous study showed that BPA administered orally at gestational stage of rats could detect not only in maternal tissues but also in fetuses, ${ }^{9)}$ indicating that BPA in maternal animals could be transferred to fetuses in gestation. Kim et al. ${ }^{10)}$ reported that the administration of $1000 \mathrm{mg} / \mathrm{kg}$ of BPA to pregnant rats occasionally induced the pregnancy failure, but $300 \mathrm{mg} / \mathrm{kg}$ of BPA did not induce these effects on fetuses. In the present study, the amount of BPA in 1\% BPA diet is equal to $1000 \mathrm{mg} / \mathrm{kg}$ of BPA, and the number of live fetuses per litter in BPA diet group was same to that in normal diet group. Therefore, $1 \%$ BPA diet was not toxic for the development of fetuses in pregnant mice.

\section{Insufficient Supply of Breast Milk from Mater- nal Mice Fed BPA Diet}

Neonatal mice depend on breast milk supplied by maternal mice, and the stomach was filled with milk in the pups. On day 1, the pups delivered from maternal mice fed normal diet showed white stomach filled with milk, but it was hard to see the white stomach in the pups from maternal mice fed BPA diet (Fig. 2A). The weight of stomach was significantly lower in pups of BPA diet group $(28.13 \pm$ $3.33 \mathrm{mg}$ ) than that of normal diet group $(46.54 \pm$ $8.41 \mathrm{mg}$ ) (Fig. 2B). Since the growth of neonatal mice completely depend on the intake of milk, the decrease in body weight in the pups of BPA diet group may be due to the insufficient supply of maternal milk in the pups.

\section{Serum Levels of Prolactin in Maternal Mice}

It is well known that prolactin positively regulate the secretion of breast milk in maternal mice. 

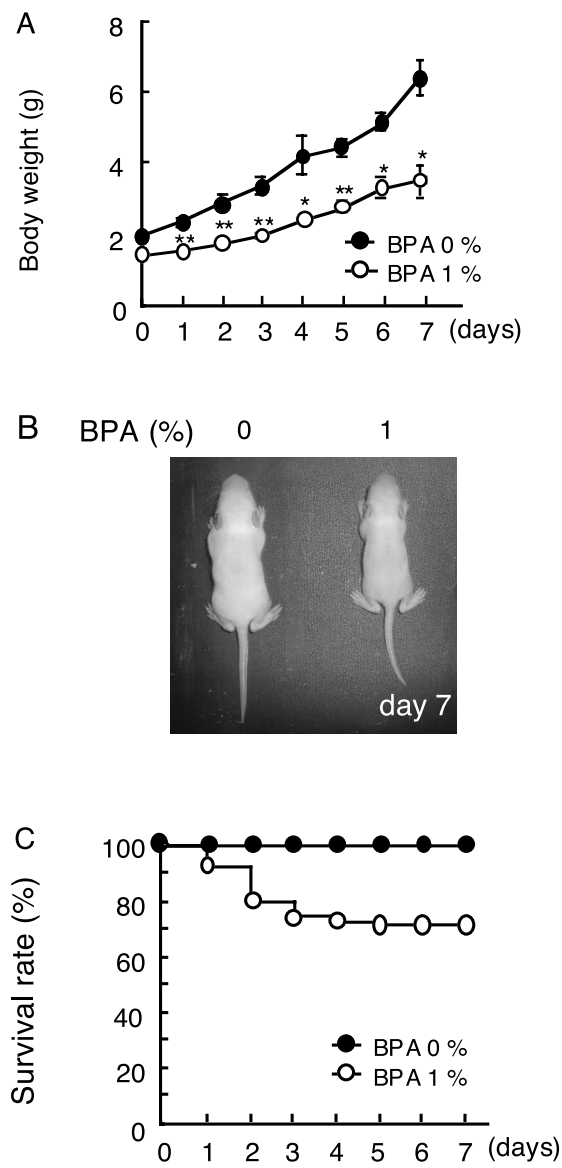

Fig. 1. Influence of Dietary BPA on the Growth and Survival of Newborn Pups in Mice

Pregnant mice were started to feed chow diet supplemented with $0 \%$ and $1 \%$ BPA on day 14 of gestation, and body weight and survival of newborn pups were monitored until day 7 after delivery. On day 21 of gestation, pregnant mice of both BPA diet and control diet groups normally delivered pups. (A) Body weight of surviving newborn pups on day 0 to 7 after delivery. Numbers of pups in 1\% BPA group are $n=$ 89 (day 0), $n=83$ (day 1), $n=70$ (day 2), $n=64$ (day 3), $n=61$ (day 4 7). Data are expressed as the means \pm SEM of 31 mice $(0 \% \mathrm{BPA})$ and 61-89 mice (1\% BPA). Significantly different from control diet groups, ${ }^{*} p<0.01$. ${ }^{* *} p<0.001$. (B) Representative picture of pups on day 7 delivered from maternal mice fed BPA diet or control diet. (C) Survival rate of newborn pups on day 0 to 7 after delivery.

When we measured serum levels of prolactin in maternal mice on day 4 after delivery, the levels of prolactin in mice fed BPA diet $(137.65 \pm 9.45 \mathrm{ng} /$ $\mathrm{ml})$ were lower than those fed control diet $(254.60 \pm$ $30.0 \mathrm{ng} / \mathrm{ml}$ ) (Fig. 3). These data are consistent with the limited weight of stomach in BPA diet group shown in Fig. 2. Prolactin-mediated secretion of breast milk may be essential for growth of neonatal pups. Effects of BPA in the production and secretion of prolactin is not clear in pituitary cells. Steinmetz et al. ${ }^{11)}$ have reported that not only $17 \beta$ estradiol (E2) but also BPA stimulates prolactin release from posterior pituitary cells, and that BPA
A
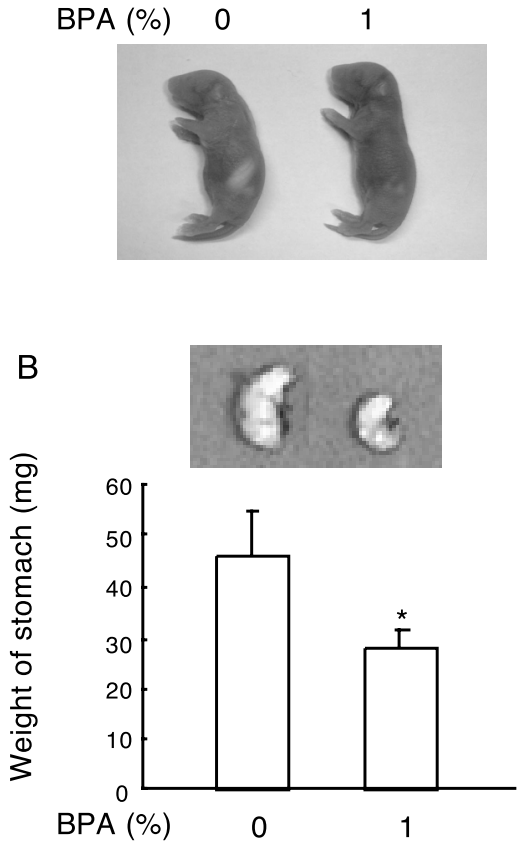

Fig. 2. Effects of Dietary BPA on the Weight of Stomach Filled with Breast Milk in Newborn Pups

(A) Representative picture of newborn pups on day 1 . White stomach filled with breast milk can be seen in pup of control diet but not in pup of BPA diet. (B) Weight of stomach in newborn pups on day 7. Data are expressed as the means \pm SEM of 10-11 mice. Significantly different from control diet groups, ${ }^{*} p<0.05$. Upper panel shows the representative picture of stomach collected from newborn pups on day 7 after delivery.

regulates transcription of prolactin through the estrogen response element. In contrast, Gould et al. ${ }^{12)}$ have reported that BPA interacts with estrogen receptor $\alpha$ in a distinct manner from estradiol. BPA, like E2, stimulated peroxidase activity and prolactin receptor in hepatoma cells, but inhibit E2-induced increase in peroxidase activity and prolactin receptor, when BPA and E2 were administered simultaneously. Therefore, effects of BPA on various tissues may be closely related to the levels of endogenous sex hormones.

The dosage of BPA, 1\% BPA, used in the present study is extremely high compared with the levels of BPA found in the environment. The amounts of BPA eluted from a polycarbonate bottle by autoclaving were reported to be $10-15 \mathrm{nM} .{ }^{13)}$ Howdeshell et al. ${ }^{3)}$ have shown that exposure of pregnant mice to environmental levels of BPA $(2.4 \mu \mathrm{g} / \mathrm{kg}$ body weight $)$ advanced the puberty of the offspring pups. However, it is still not clear whether environmental levels of BPA exhibit action as an endocrine disruptor, because possible influence of BPA in vivo may be related to the condition of sexual organs and the lev- 


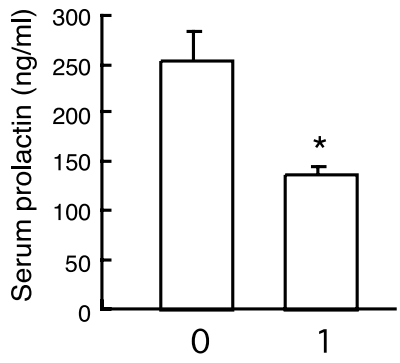

Fig. 3. Levels of Serum Prolactin in Maternal Mice on day 4 after Delivery

Data are expressed as the means \pm SEM of 3 mice. Significantly different from control diet groups, ${ }^{*} p<0.05$.

els of endogenous endocrine hormones.

In summary, when pregnant mice were fed BPA diet, the fetuses grew normally, but the growth of offspring pups was markedly suppressed probably due to the insufficient supply of breast milk. Therefore, the influence of dietary BPA in newborn pups may be related to endogenous hormones in maternal mice.

Acknowledgements The authors thank Dr. Yumiko Abe, Gunma University, for measurement of serum prolactin.

\section{REFERENCES}

1) Brotons, J. A., Olea-Serrano, M. F., Villalobos, M., Pedraza, V. and Olea, N. (1995) Xenoestrogens released from lacquer coatings in food cans. Environ. Health Perspect., 103, 608-612.

2) Kuiper, G. G., Lemmen, J. G., Carlsson, B., Corton, J. C., Safe, S. H., van der Saag, P. T., van der Burg, B. and Gustafsson, J. A. (1998) Interaction of estrogenic chemicals and phytoestrogens with estrogen receptor $\beta$. Endocrinology, 139, 4252-4263.

3) Howdeshell, K. L., Hotchkiss, A. K., Thayer, K. A., Vandenbergh, J. G. and vom Saal, F. S. (1999) Exposure to bisphenol A advances puberty. Nature (London), 401, 763-764.

4) Simpson, E. R., Mahendroo, M. S., Means, G. D., Kilgore, M. W., Hinshelwood, M. M., GrahamLorence, S., Amarneh, B., Ito, Y., Fisher, C. R. and Michael, M. D., et al. (1994) Aromatase cytochrome $\mathrm{P} 450$, the enzyme responsible for estrogen biosynthesis. Endocr. Rev., 15, 342-355.
5) Toda, K., Takeda, K., Okada, T., Akira, S., Saibara, T., Kaname, T., Yamamura, K., Onishi, S. and Shizuta, Y. (2001) Targeted disruption of the aromatase $\mathrm{P} 450$ gene (Cyp 19) in mice and their ovarian and uterine responses to $17 \beta$-oestradiol. $J$. Endocrinol., 170, 99-111.

6) Nemoto, Y., Toda, K., Ono, M., Fujikawa-Adachi, K., Saibara, T., Onishi, S., Enzan, H., Okada, T. and Shizuta, Y. (2000) Altered expression of fatty acidmetabolizing enzymes in aromatase-deficient mice. J. Clin. Invest., 105, 1819-1825.

7) Miyaura, C., Toda, K., Inada, M., Ohshiba, T., Matsumoto, C., Okada, T., Ito, M., Shizuta, Y. and Ito, A. (2001) Sex and age-related response to aromatase deficiency in bone. Biochem. Biophys. Res. Commun., 280, 1062-1068.

8) Toda, K., Miyaura, C., Okada, T. and Shizuta, Y. (2002) Dietary bisphenol A prevents ovarian degeneration and bone loss in female mice lacking the aromatase gene (Cyp19). Eur. J. Biochem., 269, 2214-2222.

9) Domoradzki, J. Y., Pottenger, L. H., Thornton, C. M., Hansen, S. C., Card, T. L., Markham, D. A., Dryzga, M. D., Shiotsuka, R. N. and Waechter, J. M., Jr. (2003) Metabolism and pharmacokinetics of bisphenol A (BPA) and the embryo-fetal distribution of BPA and BPA-monoglucuronide in CD SpragueDawley rats at three gestational stages. Toxicol. Sci., 76, 21-34.

10) Kim, J. C., Shin, H. C., Cha, S. W., Koh, W. S., Chung, M. K. and Han, S. S. (2001) Evaluation of developmental toxicity in rats exposed to the environmental estrogen bisphenol A during pregnancy. Life Sci., 69, 2611-2625.

11) Steinmetz, R., Brown, N. G., Allen, D. L., Bigsby, R. M. and Ben-Jonathan, N. (1997) The environmental estrogen bisphenol A stimulates prolactin release in vitro and in vivo. Endocrinology, 138, 1780-1786.

12) Gould, J. C., Leonard, L. S., Maness, S. C., Wagner, B. L., Conner, K., Zacharewski, T., Safe, S., McDonnell, D. P. and Gaido, K. W. (1998) Bisphenol A interacts with the estrogen receptor $\alpha$ in a distinct manner from estradiol. Mol. Cell. Endocrinol., 142, 203-214.

13) Krishnan, A. V., Stathis, P., Permuth, S. F., Tokes, L. and Feldman, D. (1993) Bisphenol-A: an estrogenic substance is released from polycarbonate flasks during autoclaving. Endocrinology, 132, 2279-2286. 